\title{
Study of Absorption Loss Effects on Acoustic Wave Propagation in Shallow Water Using Different Empirical Models
}

\author{
Yasin Yousif Al-Alaboosi ${ }^{1}$, Jenan Abdulkhalq Al-Aboosi ${ }^{2}$ \\ ${ }^{1}$ Faculty of Electrical Engineering, Universiti Teknologi Malaysia, 81310, Johor, Malaysia \\ ${ }^{2}$ Faculty of Engineering, University of Mustansiriyah, Baghdad, Iraq
}

\begin{tabular}{l}
\hline Article Info \\
\hline Article history: \\
Received Apr 20, 2017 \\
Revised Feb 23, 2018 \\
Accepted May 27, 2018 \\
\hline
\end{tabular}

Keywords:

Acoustic wave

Absorption

Boric acid

Frequency

\begin{abstract}
Efficient underwater acoustic communication and target locating systems require detailed study of acoustic wave propagation in the sea. Many investigators have studied the absorption of acoustic waves in ocean water and formulated empirical equations such as Thorp's formula, Schulkin and Marsh model and Fisher and Simmons formula. The Fisher and Simmons formula found the effect associated with the relaxation of boric acid on absorption and provided a more detailed form of absorption coefficient which varies with frequency. However, no simulation model has made for the underwater acoustic propagation using these models. This paper reports the comparative study of acoustic wave absorption carried out by means of modeling in MATLAB. The results of simulation have been evaluated using measured data collected at Desaru beach on the eastern shore of Johor in Malaysia. The model has been used to determine sound absorption for given values of depth (D), salinity (S), temperature (T), $\mathrm{pH}$, and acoustic wave transmitter frequency (f). From the results a suitable range, depth and frequency can be found to obtain best propagation link with low absorption loss.
\end{abstract}

Copyright () 2018 Institute of Advanced Engineering and Science. All rights reserved.

\section{Corresponding Author:}

Yasin Yousif Al-Alaboosi, Faculty of Electrical Engineering, Universiti Teknologi Malaysia, 81310, Johor, Malaysia.

Email: alaboosiyasin@gmail.com

\section{INTRODUCTION}

Increased interest in defense applications, off-shore oil industry, and other commercial operations provides a motivation for research in signal processing for the underwater environment. In the underwater environment, acoustics waves are more practical for applications such as navigation, communication, and other wireless applications due to the high attenuation rate of electromagnetic waves. Acoustic propagation is characterized by three major factors: attenuation that increases with signal frequency, time-varying multipath propagation, and low speed of sound (1500 m/s) [1].

The fading in underwater environment depends on the distance, frequency and sensors location, and can be divided into long term fading and short term fading. Long term fading caused by sound propagation is effected by spreading loss and absorption loss which is a function of range and frequency. Short term fading that composed of multipath and Doppler spread which is a random function of distance and time.

As the attenuation of sound in the ocean is frequency dependent, the ocean acts as a low-pass filter for ambient noise and the underwater systems operate at low frequencies, for example, on the order of tens of $\mathrm{kHz}$ [1]. No two deployment regions within the ocean with have the same depths ranging from tens of meters to a few kilometers with node placement that varies from one network to another [2]. 
Acoustic energy can be reflected and scattered from both the surface and bottom of the ocean as shown in Figure 1., permitting the possibility of more than one transmission path for a single signal [1, 2]. The phenomenon is known as multipath fading. The overlapping of consecutive pulses in digital communication results in intersymbol interference (ISI) that increases the bit-error rate in the received data [3-5]. Therefore, underwater data communication links generally support low data rates [1, 3]. This study aims to show the effects of absorption loss in propagation link between the transmitter and receiver.

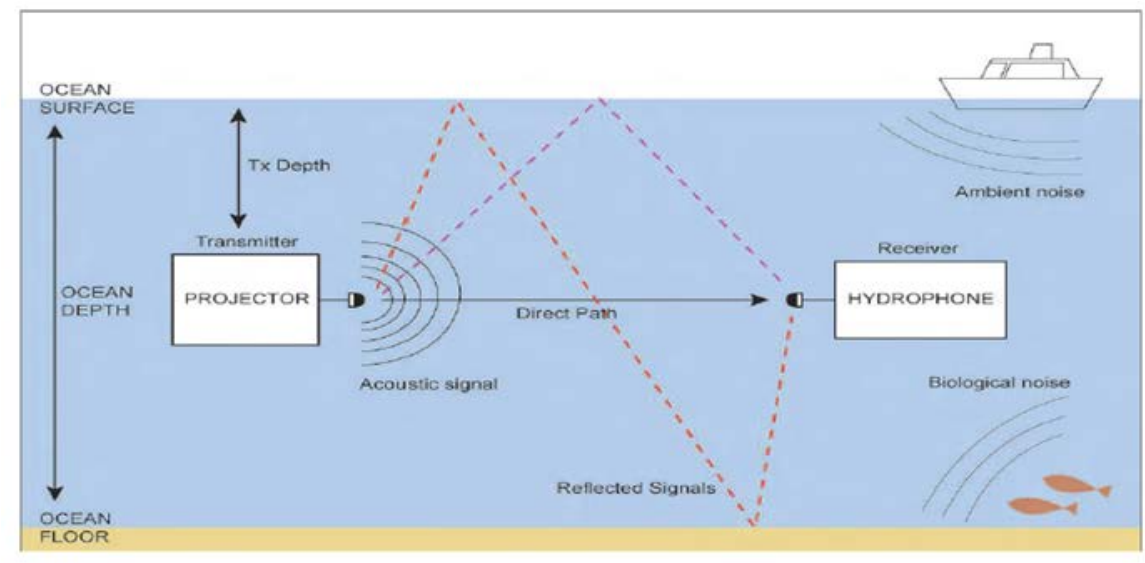

Figure 1. Underwater acoustic environment [1]

\section{RESEARCH METHOD}

\subsection{Sound Speed}

The speed of sound in seawater is a fundamental oceanographic variable that determines the behavior of sound propagation in the ocean. Many empirical formulas have been developed over the years for calculating sound speed using values of water temperature, salinity, and pressure/depth. A simplified expression for the sound speed was given by Medwin [6]:

$$
c=1449.2+4.6 T-0.055 T^{2}+0.00029 T^{3}+(1.34-0.01 T)(S-35)+0.016 d
$$

where $\mathrm{c}$ is the speed of sound in seawater, $\mathrm{T}$ is the water temperature (in degrees Celsius), $\mathrm{S}$ is the salinity (in parts per thousand) and $\mathrm{d}$ is the depth (in meters).

\subsection{Total path loss}

An acoustic signal underwater experiences attenuation due to spreading and absorption. Path loss is the measure of the lost signal intensity from the projector to the hydrophone. Spreading loss is due to the expanding area that the sound signal encompasses as it geometrically spreads outward from the source [7].

$$
P L_{\text {spreading }}(R)=k * 10 \log (R) d B
$$

where $\mathrm{R}$ is the range in meters and $\mathrm{k}$ is the spreading factor. When the medium in which signal transmission occurs is unbounded, the spreading is spherical and the spreading factor $k=2$; whereas in bounded spreading, it is considered as cylindrical $k=1$. In practice, a spreading factor of $k=1.5$ is often considered [2].

The absorption loss is a representation of the energy loss in form of heat due to viscous friction and ionic relaxation that occur as the wave generated by an acoustic signal propagates outwards; this loss varies linearly with range as follows [7]:

$$
P L_{\text {absorption }}(R, f)=10 \log (\alpha(f)) * R d B
$$

where $r$ is range in kilometres and $\alpha(f)$ is the absorption coefficient. The absorption coefficient using different emperical models will be discussed in next section.

Total path loss is the combined contribution of both the spreading and absorption losses [1]. 
Total Path Loss $=k * 10 \log (R)+10 \log (\alpha(f)) * R(d B)$

\subsection{Absorption Loss Empirical Models}

The acoustic energy of a sound wave propagating in the ocean is partly:

a. absorbed, i.e. the energy is transformed into heat.

b. lost due to sound scattering by inhomogeneities.

On the basis of extensive laboratory and field experiments the following empirical formulae for attenuation coefficient in sea water have been derived. There are three formulaes: Thorp's formula, SchulkinMarsh model and Fisher-Simmons formula and the frequency band for each one as shown in Figure 2.

R. E. Francois and G. R. Garrison [11] have formulated the equation for the sound absorption in the frequency range $400 \mathrm{~Hz}$ to $1 \mathrm{MHz}$ which includes the contribution of Boric Acid, Magnesium Sulfate and Pure water. The results given by this equation are very close to the practical results.

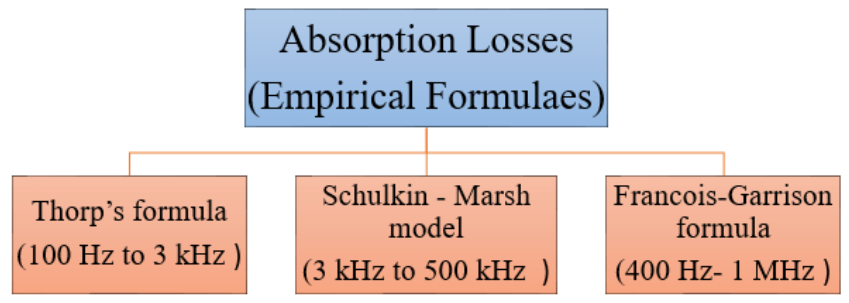

Figure 2. Diagram indicating empirical formulae for different frequency domains

The absorption coefficient for frequency range $100 \mathrm{~Hz}$ to $3 \mathrm{kHz}$ can be expressed empirically using Thorp's formula $[2,8]$ which defines $\alpha[\mathrm{dB} / \mathrm{m}]$ as a function of $\mathrm{f}[\mathrm{kHz}]$

$$
\alpha(f)=\left(0.11 \frac{f^{2}}{f^{2}+1}+44 \frac{f^{2}}{f^{2}+4100}+2.75 \cdot 10^{-4} f^{2}+0.0003\right) \cdot 10^{-3}
$$

The absorption coefficient for frequency range $3 \mathrm{kHz}$ to $500 \mathrm{kHz}$ can be expressed empirically using Schulkin and Marsh model $[2,8]$ which defines $\alpha[\mathrm{dB} / \mathrm{m}]$ as a function of $\mathrm{f}[\mathrm{kHz}]$

$$
\alpha(f)=8.686 \cdot 10^{3}\left(\frac{A f_{T^{2}} f^{2}}{f_{T}^{2}+f^{2}}+\frac{B f^{2}}{f_{T}}\right)\left(1-6.54 \cdot 10^{-4} P\right) \cdot 10^{-3}
$$

where $\mathrm{A}$ and $\mathrm{B}$ are constants $\mathrm{A}=2.34 \cdot 10^{-6}, \mathrm{~B}=3.38 \cdot 10^{-6}, \mathrm{P}$ is the hydrostatic pressure $[\mathrm{kg} / \mathrm{cm} 3]$, $\mathrm{f}_{\mathrm{T}}=21.9 .10^{\left[6-\left(\frac{1520}{\mathrm{~T}+273}\right)\right]}[\mathrm{kHz}]$ is the relaxation frequency.

An alternative expression for the absorption coefficient $\alpha(\mathrm{f})[\mathrm{dB} / \mathrm{m}]$ is given by the Fisher and Simmons formula in range of frequency $10 \mathrm{kHz}-1 \mathrm{MHz}$ [9]

$$
\alpha(\mathrm{f})=(\underbrace{\mathrm{A}_{1} \mathrm{P}_{1} \frac{\mathrm{f}^{2}}{\mathrm{f}_{1}^{2}+\mathrm{f}^{2}} \mathrm{f}_{1}}_{\mathrm{B}(\mathrm{OH})_{3}, \text { Boric acid }}+\underbrace{\mathrm{A}_{2} \mathrm{P}_{2} \frac{\mathrm{f}^{2}}{\mathrm{f}_{2}^{2}+\mathrm{f}^{2}} \mathrm{f}_{2}}_{\mathrm{MgSO}_{4}, \text { magnesium sulphate }}+\underbrace{\mathrm{A}_{3} \mathrm{P}_{3} \mathrm{f}^{2}}_{\mathrm{H}_{2} \mathrm{O} \text {, pure water }}) \cdot 10^{-3}
$$

where $A_{1}, A_{2}$ and $A_{3}$ are the coefficients represent the effects of temperature, while the $P_{1}, P_{2}$ and $\mathrm{P}_{3}$ coefficients represent ocean depth (pressure) and $\mathrm{f}_{1}, \mathrm{f}_{2}$ represent the relaxation frequencies of Boric acid and (MgSO4) molecules [9]. As a result, the absorption coefficient is proportional to the operating frequency.

1. $\quad$ Boric acid $\mathrm{B}(\mathrm{OH})_{3}$

$$
\begin{aligned}
& A_{1}=\frac{8.686}{C} \cdot 10^{0.78 p h-5} \\
& P_{1}=1
\end{aligned}
$$




$$
f_{1}=2.8 \sqrt{\frac{S}{35}} 10^{4-\frac{1245}{T+273}}
$$

2. Magnesium Sulphate MgSO4

$$
\begin{aligned}
& A_{2}=21 \cdot 44 \cdot \frac{S}{c} \cdot(1+0.025 T) \\
& P_{2}=1-1.37 \cdot 10^{-4} Z_{\text {max }}+6 \cdot 2 \cdot 10^{-9} \cdot z_{\text {max }}^{2} \\
& f_{2}=\frac{8.17 \cdot\left(10^{\left.8-\frac{1990}{(T-273)}\right)}\right.}{1+0.0018(S-35)}
\end{aligned}
$$

3. Pure water $\mathrm{H}_{2} \mathrm{O}$

$$
\begin{aligned}
& A_{3}=\left\{\begin{array}{c}
4.937 \cdot 10^{-4}-2.59 \cdot 10^{-5} T+9.11 \cdot 10^{-7} T^{2}-1.5 \cdot 10^{-8} T^{3} \text { for } T \leq 20^{\circ} C \\
3.964 \cdot 10^{-4}-1.146 \cdot 10^{-5} T+1.45 \cdot 10^{-7} T^{2}-6.5 \cdot 10^{-8} T^{3} \text { for } T \geq 20^{\circ} C
\end{array}\right\} \\
& P_{3}=1-3.83 \cdot 10^{-5} z_{\max }+4.9 \cdot 10^{-10} \cdot z_{\max }^{2}
\end{aligned}
$$

with $\mathrm{f}$ in $[\mathrm{kHz}], \mathrm{T}$ in $\left[{ }^{\circ} \mathrm{C}\right], \mathrm{S}$ in [ppt]. And where $z_{\max }, \mathrm{pH}$ and c denote the depth in [m], the pH-value and the sound speed in $[\mathrm{m} / \mathrm{s}]$ respectively.

R. E. Francois and G. R. Garrison [11] have formulated the equation for the sound absorption in the frequency range $400 \mathrm{~Hz}$ to $1 \mathrm{MHz}$ which includes the contribution of Boric Acid, Magnesium Sulfate and Pure water. The results given by this equation are very close to the practical results.

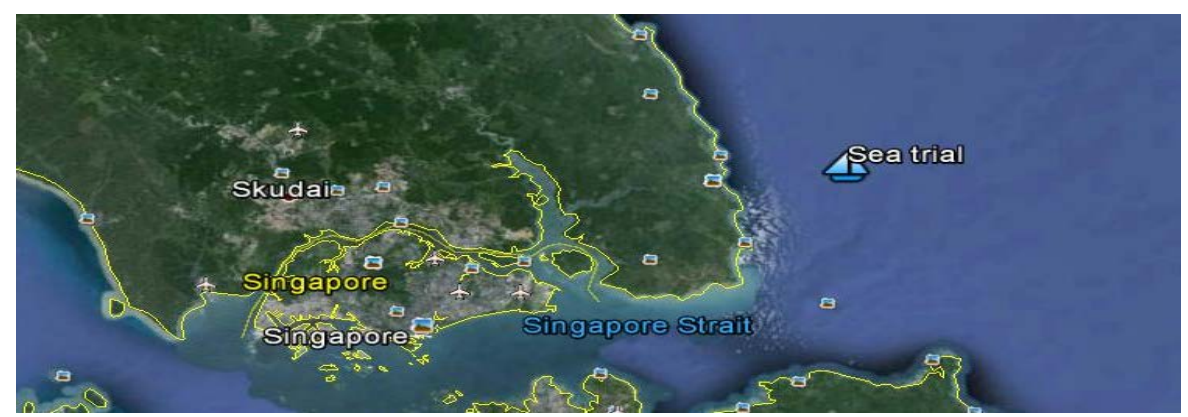

Figure 3. Experiment test site

A general diagram showing the variation of $\alpha(f)$ using Francois and G. R. Garrison formula with the three regions of Boric acid, $\mathrm{B}(\mathrm{OH})_{3}$, Magnesium sulphate, $\mathrm{MgSO}_{4}$ and Pure water, $\mathrm{H}_{2} \mathrm{O}$ is depicted in Figure 4. It can be observed that for the Boric acid region, Attenuation is proportional to $f^{2}$. And for the regions Magnesium sulphate and pure water also Attenuation is proportional to $f^{2}$. In the transition domains it is proportional to $f$.

With fixed the range at $1000 \mathrm{~m}$, the path loss is proportional to the operating frequency and it is increased when the operating frequency increased and the contribution of the absorption term is less significant than the spreading term as shown in Figure 5.

Figure 6. and Figure 7. with fixed the range at $10 \mathrm{Km}$ and $100 \mathrm{Km}$ respectively. As range increases and the absorption term begins to dominate, any variations in $\alpha$ also becomes more significant. For data communication, the changes in the attenuation due to signal frequency are particularly important as the use of higher frequencies will potentially provide higher data rates.

The total path loss versus the range at different frequencies shown in Figure 8. The path losses Increase significantly at high frequency compared with low frequency. Therefore, the attenuation of sound in the sea is frequency dependent, the sea acts as a low-pass filter. 


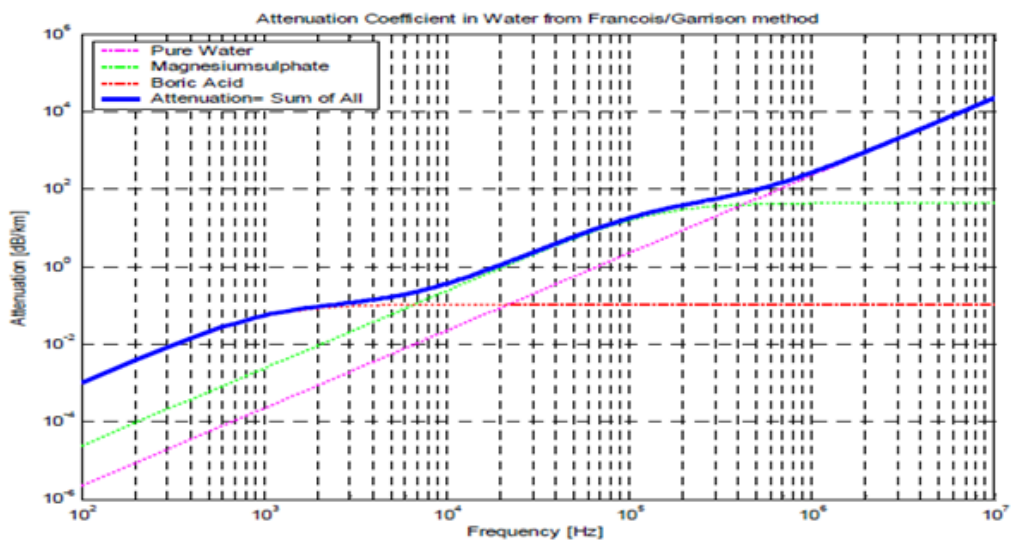

Figure 4. General diagram indicating the three regions of $\mathrm{B}(\mathrm{OH}) 3, \mathrm{MgSO} 4$ and $\mathrm{H} 2 \mathrm{O}$

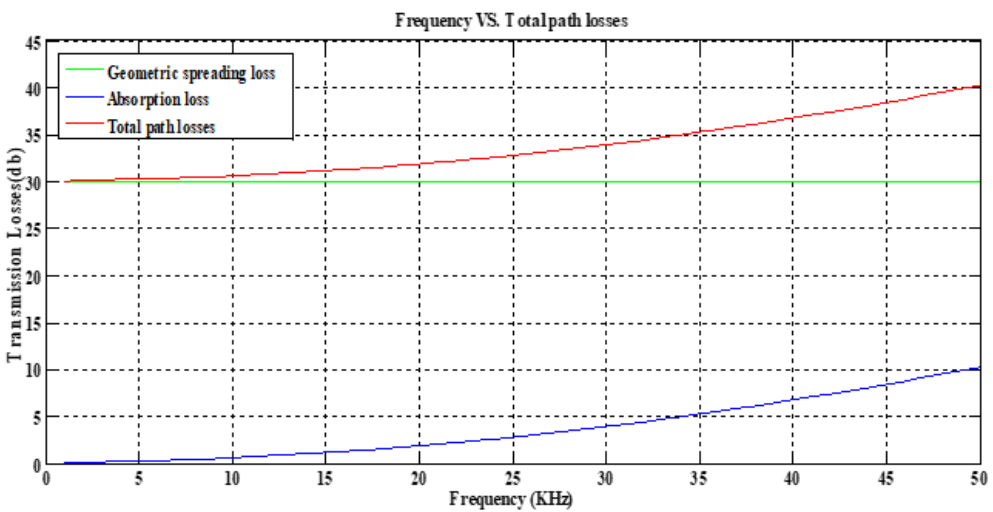

Figure 5. Total path losses as a function of frequency with range $1 \mathrm{Km}$

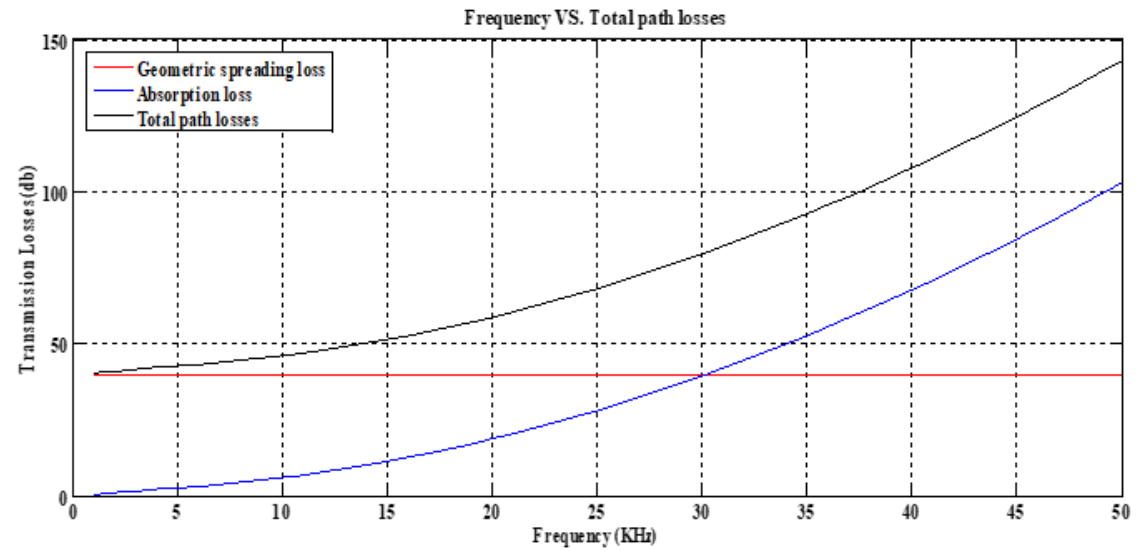

Figure 6. Total path losses as a function of frequency with range $10 \mathrm{Km}$ 


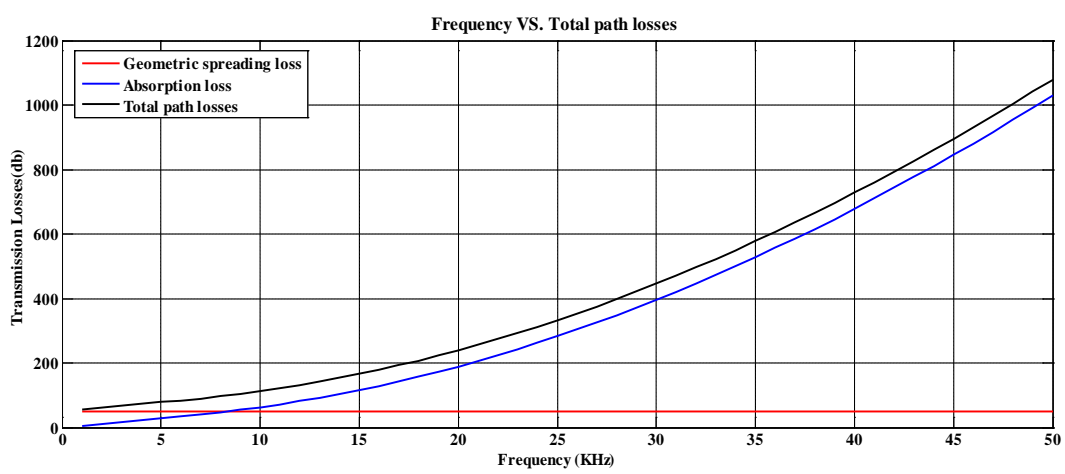

Figure7. Total path losses as a function of frequency with range $10 \mathrm{Km}$

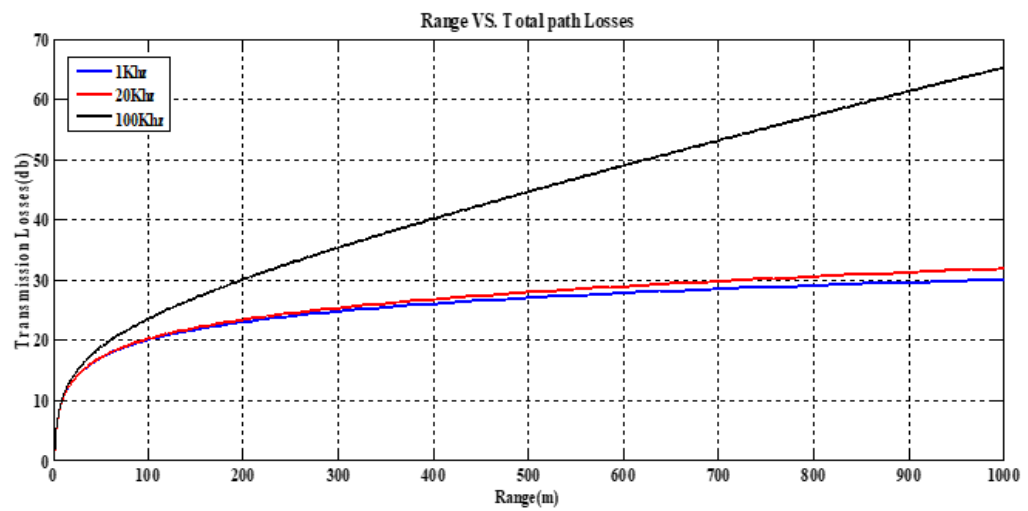

Figure 8. Total path losses as a function of range

\section{CONCLUSION}

In this paper, the losses due to phenomena of acoustic wave propagation and absorption have been studied. The absorption coefficients in $\mathrm{dB} / \mathrm{km}$ vs signal frequency for Francois and G. R. Garrison formula shows that in general $\alpha$ increases with increasing frequency at any fixed temperature and depth. For very short-range communication, the contribution of the absorption term is less significant than the spreading term. As range increases, the absorption term begins to dominate, any variations in $\alpha$ also becomes more significant. For data communication, the changes in the attenuation due to signal frequency are particularly important as the use of higher frequencies will potentially provide higher data rates. Nevertheless, no other type of radiation can compete with low-frequency sound waves to communicate over great distances in oceanic environment.

\section{REFERENCES}

[1] G. Burrowes and J. Y. Khan, Short-range underwater acoustic communication networks: INTECH Open Access Publisher, 2011.

[2] T. Melodia, H. Kulhandjian, L.-C. Kuo, and E. Demirors, "Advances in underwater acoustic networking," Mobile Ad Hoc Networking: Cutting Edge Directions, pp. 804-852, 2013.

[3] B. Borowski, "Characterization of a very shallow water acoustic communication channel," in Proceedings of MTS/IEEE OCEANS, 2009.

[4] P. S. Naidu, Sensor array signal processing: CRC press, 2009.

[5] E. An, "Underwater Channel Modeling for Sonar Applications," MSc Thesis, The Graduate School of Natural and Applied Sciences of Middle East Technical University, 2011.

[6] H. Medwin and C. S. Clay, Fundamentals of acoustical oceanography: Academic Press, 1997.

[7] F. De Rango, F. Veltri, and P. Fazio, "A multipath fading channel model for underwater shallow acoustic communications," in Communications (ICC), 2012 IEEE International Conference on, 2012, pp. 3811-3815.

[8] W. H. Thorp, "Analytic Description of the Low Frequency Attenuation Coefficient," The Journal of the Acoustical Society of America, vol. 42, pp. 270-270, 1967.

[9] F. Fisher and V. Simmons, "Sound absorption in sea water," The Journal of the Acoustical Society of America, vol. 62, pp. 558-564, 1977. 